\section{Internephron Heterogeneity for Carbonic Anhydrase-independent Bicarbonate Reabsorption in the Rat}

\author{
J. Pedro Frommer, Melvin E. Laski, Donald E. Wesson, \\ and Neil A. Kurtzman \\ With the technical assistance of Mary Ann Dudek \\ Section of Nephrology, Department of Medicine, University of \\ Illinois College of Medicine, Chicago, Illinois 60612
}

A signed to localize the sites of carbonic anhydrase-independent bicarbonate reabsorption in the rat kidney and to examine some of its mechanisms. Young MunichWistar rats were studied using standard cortical and papillary free-flow micropuncture techniques. Total $\mathrm{CO}_{2}$ $\left(\mathrm{tCO}_{2}\right)$ was determined using microcalorimetry. In control rats both superficial and juxtamedullary proximal nephrons reabsorbed $\sim 95 \%$ of the filtered load of bicarbonate. The administration of acetazolamide $(20 \mathrm{mg} / \mathrm{kg}$ body weight [bw]/h) decreased proximal reabsorption to $65.6 \%$ of the filtered load in superficial nephrons (32\% was reabsorbed by the proximal convoluted tubule while $31.7 \%$ was reabsorbed by the loop segment), and to $38.4 \%$ in juxtamedullary nephrons. Absolute reabsorption of bicarbonate was also significantly higher in superficial than in juxtamedullary nephrons after administration of acetazolamide ( $727 \pm 82$ vs. $346 \pm 126 \mathrm{pmol} / \mathrm{min} ; P<0.05)$. The infusion of amiloride $(2.5 \mathrm{mg} / \mathrm{kg} \mathrm{bw} / \mathrm{h})$ to acetazolamide-treated rats increased the fractional excretion of bicarbonate as compared with animals treated with acetazolamide alone $(34.9 \pm 1.9$ vs. $42.9 \pm 2.1 \% ; P<0.01)$, and induced net addition of bicarbonate between the superficial early distal tubule and the final urine $(34.8 \pm 3.0$ vs. $42.9 \pm 2.1 \% ; P<0.05$ ). Amiloride at this dose did not affect proximal water or bicarbonate transport; our studies

Portions of these studies were presented at the Midwest Section, American Federation for Clinical Research, November 3-6, 1982, and at the 40th Annual Meeting of the American Federation for Clinical Research, April 28-May 2, 1983, and are published in Abstract form.

Address correspondence and reprint requests to Dr. Frommer, Renal Section (151-B), V.A. Medical Center, Houston, TX 77211.

Received for publication 13 May 1983 and in revised form 18 November 1983.

J. Clin. Invest.

(C) The American Society for Clinical Investigation, Inc.

$0021-9738 / 84 / 04 / 1034 / 12 \$ 1.00$

Volume 73, April 1984, 1034-1045 localize its site of action to the terminal nephron. Vasa recta (VR) plasma and loop of Henle (LH) tubular fluid $\mathrm{tCO}_{2}$ were determined in control and acetazolamidetreated rats in order to identify possible driving forces for carbonic anhydrase-independent bicarbonate reabsorption in the rat papilla. Control animals showed a $\mathrm{tCO}_{2}$ gradient favoring secretion $\left(\mathrm{LH} \mathrm{tCO} \mathrm{tC}_{2}, 7.4 \pm 1.7 \mathrm{mM}\right.$ vs. VR tCO $2,19.1 \pm 2.3 \mathrm{mM} ; P<0.005)$. Acetazolamide administration reversed this chemical concentration gradient, inducing a driving force favoring reabsorption of bicarbonate $\left(\mathrm{LH} \mathrm{tCO}_{2}, 27.0 \pm 1.4 \mathrm{mM}\right.$ vs. VR $\mathrm{tCO}_{2}$, $20.4 \pm 1.0 \mathrm{mM} ; P<0.005$ ).

Our study shows that in addition to the superficial proximal convoluted tubule, the loop segment and the collecting duct show acetazolamide-insensitive bicarbonate reabsorption. No internephron heterogeneity for bicarbonate transport was found in controls. The infusion of acetazolamide, however, induced significant internephron heterogeneity for bicarbonate reabsorption, with superficial nephrons reabsorbing a higher fractional and absolute load of bicarbonate than juxtamedullary nephrons. We think that the net addition of bicarbonate induced by amiloride is secondary to inhibition of voltagedependent, carbonic anhydrase-independent bicarbonate reabsorption at the level of the collecting duct, which uncovers a greater delivery of bicarbonate from deeper nephrons to the collecting duct.

Finally, our results suggest that carbonic anhydraseindependent bicarbonate reabsorption is partly passive, driven by favorable chemical gradients in the papillary tubular structures, and partly voltage-dependent, in the collecting duct.

\section{Introduction}

It is now well known that the bulk of bicarbonate reabsorption by the mammalian kidney occurs in the proximal tubule by mechanisms that are strongly dependent on the activity of the enzyme carbonic anhydrase (1-8). Free-flow micropuncture 
studies have established that inhibition of carbonic anhydrase will result in a decrease of bicarbonate reabsorption by the proximal tubule to $\sim 20 \%$ of the filtered load $(2,3,7)$. In vivo and in vitro microperfusion studies of the proximal tubule of the rat and the rabbit have shown up to $100 \%$ inhibition of bicarbonate reabsorption after inhibition of carbonic anhydrase ( 1 , $4-6,8)$. In spite of the fact that $\sim 80 \%$ of the filtered load of bicarbonate is delivered to the late portions of the superficial proximal tubule accessible to micropuncture, only $20-30 \%$ of the filtered load is excreted in the final urine $(2,7)$. Thus, $\sim 50 \%$ of the filtered load of bicarbonate can be reabsorbed in the kidney by mechanisms that are independent of the enzyme carbonic anhydrase, and at tubular sites other than the superficial proximal convoluted tubule.

The present free-flow micropuncture study was designed to localize the tubular sites of carbonic anhydrase-independent bicarbonate reabsorption in the rat. Recent work by DuBose and Lucci (7) has demonstrated that, besides the superficial proximal convoluted tubule, both the loop segment of superficial nephrons and the terminal nephron reabsorb significant amounts of bicarbonate after inhibition of carbonic anhydrase with acetazolamide. The mechanisms of carbonic anhydrase-independent bicarbonate reabsorption have not been well defined. The uncatalyzed reaction is clearly insufficient to account for the observed rates of bicarbonate reabsorption $(8,9)$. Several explanations have been proposed such as incomplete inhibition of the enzyme, direct bicarbonate reabsorption (rather than hydrogen ion secretion), and hydrogen ion secretion, maintained by recycling of carbonic acid $(9,10)$. DuBose and Lucci (7) suggest that the establishment of bicarbonate gradients between the loop of Henle (LH) ${ }^{1}$ and vasa recta (VR) may be one of the mechanisms driving carbonic anhydrase-independent bicarbonate reabsorption.

Previous studies have established that there is internephron heterogeneity in the renal handling of diverse solutes (11). Using the isolated tubule microperfusion technique, Jacobson (6) and Warnock and Burg (12) have demonstrated internephron heterogeneity for bicarbonate reabsorption in the proximal tubule of the rabbit. Jacobson (6) observed that this heterogeneity persists after inhibition of carbonic anhydrase with acetazolamide. DuBose and Lucci (7), using free-flow micropuncture in the rat, postulate that the proximal tubules of juxtamedullary nephrons have a greater capacity than those of superficial nephrons to reabsorb bicarbonate independently of carbonic anhydrase. We sought to examine this issue and the role of juxtamedullary nephrons in both carbonic anhydrase-dependent and -independent bicarbonate reabsorption, by sampling the LH of juxtamedullary nephrons. In an effort to precisely localize the sites

1. Abbreviations used in this paper: bw, body weight; $\mathrm{CD}$, collecting duct; $\mathrm{FE}$, fractional excretion; $\mathrm{FRH}_{2} \mathrm{O}$, fractional reabsorption of water; GFR, glomerular filtration rate; $L H$, loop of Henle; $P_{o s m}$, plasma osmolality; SNGFR, single nephron glomerular filtration rate; TF $/ P_{\text {In }}$, TF to $P_{\text {In }}$ ratio; $t \mathrm{tO}_{2}$, total $\mathrm{CO}_{2} ; \mathrm{TF}$, tubular fluid; $\mathrm{V}$, urine flow; $\mathrm{U}_{\text {osm }}$, urine osmolality; VR, vasa recta. of carbonic anhydrase-independent bicarbonate reabsorption by the terminal nephron and to estimate the voltage-dependence of this process, we also studied a group of animals simultaneously infused with acetazolamide and amiloride. The diuretic amiloride inhibits sodium reabsorption at the level of the cortical collecting tubule and abolishes the lumen-negative transepithelial potential difference (13).

Our results show that $(a)$ No internephron heterogeneity for bicarbonate transport was found with the present technique under control conditions in the rat. There is internephron heterogeneity for carbonic anhydrase-independent bicarbonate reabsorption, with superficial nephrons reabsorbing more bicarbonate than juxtamedullary nephrons both in fractional and absolute terms. (b) The loop segment reabsorbs a significant amount of the filtered load of bicarbonate under conditions of carbonic anhydrase inhibition. (c) The terminal nephron, probably the cortical collecting tubule, has capacity for carbonic anhydrase-independent bicarbonate reabsorption by mechanisms that may be at least partly voltage-dependent. (d) Acetazolamide administration reverses the chemical concentration gradients between papillary tubular segments and VR blood, generating a driving force that favors passive bicarbonate reabsorption.

\section{Methods}

\section{Preparation protocol}

79 female Munich-Wistar rats (Timco Breeding Laboratories, Houston, TX) weighing between 110 and $160 \mathrm{~g}$ were studied. These animals were fed a standard Ralston Purina chow diet (Ralston Purina Co., St. Louis, MO) and allowed free access to tap water until the time of the experiment. They were anesthetized by an intraperitoneal injection of sodium ethyl(1-methyl propyl)-malonyl thiourea (Inactin, BYK, Hamburg, Federal Republic of Germany) $(100 \mathrm{mg} / \mathrm{kg}$ body weight [bw]) and prepared for micropuncture. The rats were then placed on a thermostatically controlled heating table and body temperature was kept constant at $37^{\circ} \mathrm{C}$. A tracheostomy tube was inserted. Four venous jugular catheters (PE-50) were inserted for the infusion of different solutions. A right carotid arterial catheter was inserted for monitoring of arterial blood pressure and withdrawal of blood samples. A bladder catheter (PE-90) was inserted for the collection of urine samples. A left flank incision was performed, the left kidney isolated, and the capsule separated by gentle blunt disection. The kidney was then placed in a Lucite cup, immobilized in $2 \%$ agar in saline, and illuminated with a fiberoptic source (American Optical Corp., Southbridge, MA). The left ureter was isolated, cleaned, and a loose ligature was placed around it. The surface and papilla of the kidney and abdominal contents of the rat were bathed by a constant drip of warm mineral oil, equilibrated with water, and bubbled with $6.7 \% \mathrm{CO}_{2}$ gas. $^{2}$ All animals received the following infusions: a solution of $0.9 \%$ normal saline, $2 \% \mathrm{bw}$, in the course of $30 \mathrm{~min}$ to replace surgical losses; and a $1.3-\mathrm{ml}$ bolus injection of $\left[{ }^{3} \mathrm{H}\right]$ inulin $(75 \mu \mathrm{Ci} / \mathrm{ml})(\mathrm{New}$ England Nuclear, Boston, MA) in normal saline, followed by a constant infusion of the same solution at a rate of $1.3 \mathrm{ml} / \mathrm{h}$. Replacement of surgical losses with normal saline solution, $2 \%$ of bw, restored the he-

2. All mineral oil in contact with the kidney surfaces or samples was bubbled with $6.7 \% \mathrm{CO}_{2}$ in order to achieve a $\mathrm{PCO}_{2}$ of $60-70 \mathrm{mmHg}$, similar to that reported in tubular fluid of the kidney cortex $(14,15)$. 
matocrit to base-line values characteristic of conscious rats (16). After $1 \mathrm{~h}$ of equilibration the ligature around the left ureter was tightened, the ureter opened, and the left papilla exposed and bathed with a constant drip of warm mineral oil. All animals with a proximal lissamine green transit time of more than $15 \mathrm{~s}$, with retention of lissamine green, or a mean arterial blood pressure below $100 \mathrm{mmHg}$, were discarded from the study.

Two 30-min clearance collections were performed. Urine from the contralateral kidney was collected under oil. Arterial blood $(0.4 \mathrm{ml})$ was obtained in the middle of each period for determinations of $\mathrm{pH}, \mathrm{PCO}_{2}$, and electrolytes, and replaced with equivalent amounts of normal saline solution. Tail vein blood was also obtained in the middle of each period to determine plasma inulin concentration. Micropuncture samples were obtained from the late proximal and early distal segments of superficial tubules, and bend of the LH of juxtamedullary nephrons. Micropuncture sites in the superficial nephrons were localized by observing the passage of lissamine green $(0.2 \%)$, which was injected intravenously as small bolus doses of $0.02 \mathrm{ml}$. The superficial late proximal tubules were localized after injection of lissamine green, by their typical appearance near "star" vessels, and confirmed by failure of an injected small droplet of Sudan black-stained mineral oil to resurface in subsequent tubular convolutions. Superficial early distal tubules were localized as the first tubules in which lissamine green could be observed after the initial total disappearance from the kidney surface. The LH of juxtamedullary nephrons were localized visually. A small droplet of Sudan black-stained mineral oil was injected into the puncture site to determine the direction of flow. After this, a droplet of the same oil of $\sim 3-4$ tubular diameters in length was injected and aspiration of the tubular fluid (TF) begun. Exactly timed collections of TF were obtained; they lasted between 3 and $6 \mathrm{~min}$. If more than minimal suction was required to collect the TF and maintain the oil block in position, the sample was discarded.

Samples from descending or ascending vasa recta were collected in pipettes according to the technique described by Johnston et al. (17). Briefly, an 8-12 $\mu \mathrm{m}$ tip diameter pipette was introduced into a VR of the papilla. If the selected vessel was a descending VR, the collection rates were slowed as suggested by these investigators in order to allow for osmotic equilibration. Samples in which there was any technical problem for collection were discarded. Immediately after collection, the tip of the pipette was sealed, the samples centrifuged for $10 \mathrm{~min}$, and the plasma collected in quartz capillary tubing. At the end of the experiment, the kidneys were excised, blotted, and weighed.

\section{Experimental protocols}

Group I. Controls $(\mathrm{n}=18$ ). These animals were maintained with an infusion of normal saline solution at a rate of $1.3 \mathrm{ml} / \mathrm{h}$. This rate of volume replacement resulted in a constant hematocrit comparable to the euvolemic rats described by Ichikawa et al. (16).

Group II. Acetazolamide $(n=33)$. These animals received a bolus intravenous injection of acetazolamide (Diamox, Lederle Laboratories, Div. American Cyanamid Co., Pearl River, NY) $(20 \mathrm{mg} / \mathrm{kg}$ bw) in Ringer's bicarbonate, followed by an hourly infusion of $20 \mathrm{mg} / \mathrm{kg}$ bw. A solution of $170 \mathrm{mmol} \mathrm{NaHCO}$ and $25 \mathrm{mmol}$ of potassium chloride was administered at a rate of $0.1 \mathrm{ml} / \mathrm{min}$ in order to replace losses and maintain constant plasma bicarbonate levels.

Group III. Acetazolamide and amiloride $(\mathrm{n}=28)$. These rats received the same amount of acetazolamide as described for group II, but in addition received a bolus dose of amiloride $(2.5 \mathrm{mg} / \mathrm{kg}$ bw) (Merck \& Co., Inc., Sharp \& Dohme Div., West Point, PA) in Ringer's bicarbonate solution, followed by an infusion of the same drug at an hourly rate of $2.5 \mathrm{mg} / \mathrm{kg}$ bw. In this group of rats, amiloride and acetazolamide were given in the same syringe and the concentration of the drugs was doubled so these animals received the same amount of fluid as the rats treated with acetazolamide alone. A solution of $170 \mathrm{mmol} \mathrm{NaHCO}_{3}$ without potassium chloride was administered at a rate of $0.1 \mathrm{ml} / \mathrm{min}$ in order to replace urinary losses and keep plasma bicarbonate levels constant.

\section{Analytical}

Immediately after the termination of the experiment, the TF and VR plasma samples were deposited on siliconized glass slides under mineral oil equilibrated with a $100 \mathrm{mM}$ Hepes ( $N-2$ hydroxyethyl piperazine$N-2$ ethanesulfonic acid) buffer solution. The total volume of the TF samples was determined using quartz capillary tubing of constant bore, which had been previously calibrated with $\left[{ }^{3} \mathrm{H}\right]$ inulin. A measured portion of the samples was used for determination of $\left[{ }^{3} \mathrm{H}\right]$ inulin activity in 5 $\mathrm{ml}$ of Scintivers (Fisher Scientific Co., Pittsburgh, PA). The samples were counted in a Beckman LS100C liquid scintillation counter (Beckman Instruments, Lincolnwood, IL). A 15-nl aliquot was taken for total $\mathrm{CO}_{2}\left(\mathrm{tCO}_{2}\right)$ determinations. $\mathrm{tCO}_{2}$ measurements of tubular fluid and VR plasma samples were performed by micro-calorimetry (Picapnotherm, Microanalytic Instruments, Bethesda, MD) as described by Vurek et al. (18). $\mathrm{tCO}_{2}$ in a sample represents bicarbonate plus the dissolved $\mathrm{CO}_{2}$ gas. Under the present experimental conditions the $\mathrm{tCO}_{2}$ concentration was taken to represent the bicarbonate concentration in the sample. Contamination of VR samples by collecting duct fluid was ruled out by using the formula suggested by Johnston et al. (17), $\left(V_{R_{I n}}-P_{I n}\right) /$ $\left(C D_{I n}\right) \times 100$, where $I n$ is inulin, and $P$ is plasma. $C D_{\text {In }}$ was determined from base and tip of papillary CD samples obtained in each animal. All samples that had a value higher than $5 \%$ were discarded.

Urine and arterial blood $\mathrm{pH}$ and $\mathrm{PCO}_{2}$ were determined immediately after collection in a blood gas analyzer (Radiometer Co., Copenhagen, Denmark); urine and plasma, sodium and potassium concentrations were measured by flame photometry (IL Autocal flame photometer, Instrumentation Laboratory, Inc., Lexington, MA); urine and plasma chloride concentrations were determined in a chloridometer (Corning Medical \& Scientific, Medfield, MA); plasma protein concentration was determined by refractometry; and plasma osmolality $\left(\mathrm{P}_{\mathrm{osm}}\right)$ and urine osmolality $\left(\mathrm{U}_{\mathrm{osm}}\right)$ were measured by a vapor pressure osmometer (Wescor Inc., Logan, UT).

\section{Calculations}

The single nephron glomerular filtration rate (SNGFR) and whole kidney GFR were estimated from the single nephron and whole kidney inulin clearances, respectively. SNGFR from early distal tubules was used to calculate absolute proximal bicarbonate reabsorption by superficial nephrons. Fractional reabsorption of water $\left(\mathrm{FRH}_{2} \mathrm{O}\right)$ was calculated as $\left(1-\mathrm{P} / \mathrm{TF}_{\mathrm{In}}\right) \times 100$. The absolute reabsorption of $\mathrm{tCO}_{2}$ was determined from the difference between the filtered $\mathrm{tCO}_{2}$ (SNGFR $\times$ plasma bicarbonate) and the $\mathrm{tCO}_{2}$ delivered to the micropuncture site (flow rate $x+\mathrm{tCO}_{2}$ concentration at the micropuncture site). The fractional delivery of $\mathrm{tCO}_{2}\left(\mathrm{FDtCO}_{2}\right)$ to the different micropuncture sites was calculated as $[\mathrm{TF} / \mathrm{P}] \mathrm{tCO} / \mathrm{In}$. Results were factored by gram kidney weight.

The term "proximal reabsorption" in this paper refers to the amount of water or bicarbonate reabsorbed by the proximal convoluted tubule, pars recta, and thin descending limb of Henle's loop of both superficial and juxtamedullary nephrons. Thus, proximal reabsorption or delivery of bicarbonate in superficial nephrons was calculated on the basis of the amount of the anion delivered to the superficial early distal micropuncture site. These results were compared with those obtained at the bend of the LH of juxtamedullary nephrons. Since the bend of the LH of superficial nephrons is inaccessible to micropuncture, proximal bi- 
carbonate reabsorption by superficial and juxtamedullary nephrons can only be compared by determining bicarbonate reabsorption at either the late proximal site or the early distal site of superficial nephrons. We thought that the early distal site better represented proximal bicarbonate reabsorption by superficial nephrons since both clearance and in vitro microperfusion studies suggest that bicarbonate is very poorly reabsorbed by the ascending limb of the LH (19-22). By the same token, the ascending limb of the LH is impermeable to water $(23,24)$. Thus, delivery of water to the early distal site represents delivery to the bend of the $\mathrm{LH}$ of superficial nephrons. We have calculated proximal $\mathrm{FRH}_{2} \mathrm{O}$ from water delivery to the early distal site in superficial nephrons and to the LH in juxtamedullary nephrons.

Urine and blood bicarbonate concentrations were calculated from the $\mathrm{pH}$ and $\mathrm{PCO}_{2}$ according to the Henderson-Hasselbalch equation. A $\mathrm{pK}$ of 6.1 was used for blood. A pK of $6.33-0.5 \sqrt{\mathrm{B}}$ was used for urine, where $B$ represents the total cation concentration, estimated as the sum of sodium plus potassium expressed in equivalents per liter. A solubility coefficient of 0.0301 for blood and 0.0309 for urine was used to convert $\mathrm{CO}_{2}$ tension to $\mathrm{H}_{2} \mathrm{CO}_{3}(25)$. The fractional excretion (FE) of bicarbonate was determined from the clearance of bicarbonate by the intact contralateral kidney divided by the GFR. Vasa recta plasma $\mathrm{tCO}_{2}$ was corrected for plasma water using a water correction factor of 0.93 (assuming a VR plasma protein concentration of $7 \mathrm{~g} / \mathrm{dl}$ ) (17). This probably overestimates VR $\mathrm{tCO}_{2}$. No correction was done for GibbsDonnan equilibrium since the interstitial protein concentration was not known.

Results are expressed as mean \pm SEM. The results of the individual tubules were averaged for each animal. Statistical significance was determined using $t$ test for paired or unpaired observations where appropriate. Analysis of variance was used when more than two means were compared. A test for interaction in an unbalanced two-way analysis of variance was employed to compare the loop segment $\mathrm{tCO}_{2}$ reabsorption of control and acetazolamide-treated animals (26).

\section{Results}

\section{Whole animal data}

Table I depicts the systemic blood and urine data for the three groups of animals. Plasma electrolytes and osmolality, plasma protein, hematocrit, and GFR were unchanged. Urine flow (V) and $\mathrm{FE}_{\mathrm{Na}}$ were significantly higher and $\mathrm{U}_{\mathrm{osm}}$ significantly lower $(P<0.005)$ for the experimental groups II and III as compared with control. $\mathrm{V}, \mathrm{FE}_{\mathrm{Na}}$, and $\mathrm{FE}_{\mathrm{Cl}}$ were higher in group III as compared with group II $(P<0.005)$. On the other hand, $\mathrm{FE}_{\mathrm{K}}$ and $\mathrm{U}_{\text {osm }}$ were lower in group III as compared with group II ( $P$ $<0.005$ ). The decrease in $\mathrm{FE}_{\mathrm{K}}$ in the amiloride-treated group is an expected finding.

Table II depicts the whole animal acid-base data. Arterial $\mathrm{pH}$ and plasma bicarbonate were unchanged as compared with control. Arterial $\mathrm{pCO}_{2}$ was significantly elevated in group II. This effect of acetazolamide on $\mathrm{ApCO}_{2}$ is secondary to its inhibitory effect on erythrocyte carbonic anhydrase and is consistent with the results of other investigators $(2,7)$. No bicarbonate was present in the urine of almost every control animal. The administration of acetazolamide increased the $\mathrm{FEHCO}_{3}$ $(34.9 \pm 1.9 \%)$ to levels similar to those previously reported by other laboratories $(2,7)$. The addition of amiloride to acetazolamide (group III) induced a further significant increment in $\mathrm{FEHCO}_{3}(42.9 \pm 2.1 \% ; P<0.01$ vs. group II).

\section{Micropuncture data}

Table III summarizes the micropuncture data. Superficial and juxtamedullary nephron samples were obtained from different animals most of the time. $T F / P_{I n}$ values at the three sites of

Table I. Systemic Blood and Urine Data

\begin{tabular}{|c|c|c|c|c|c|c|c|c|c|c|c|}
\hline & $P_{\mathrm{Ne}}$ & $\mathbf{P}_{\mathbf{k}}$ & $\mathrm{Hct}$ & P prot & $\mathbf{v}$ & GFR & $\mathrm{FE}_{\mathrm{Na}}$ & $\mathrm{FE}_{\mathrm{k}}$ & $\mathrm{FE}_{\mathrm{a}}$ & $P_{\text {osm }}$ & $\mathrm{U}_{\text {oum }}$ \\
\hline & $m e q / l$ & $m e q / l$ & $\%$ & $g / d l$ & $\mu l / m i n$ & $\mu l / m i n / g k w$ & $\%$ & $\%$ & $\%$ & mosmol & mosmol \\
\hline \multicolumn{12}{|c|}{ Group I (control) $(n=18)$} \\
\hline $\mathbf{M}$ & 145 & 5.4 & 46 & 2.7 & 7.3 & 1016 & 0.6 & 20.2 & 1.5 & 306 & 1276 \\
\hline SEM & 2 & 0.3 & 1 & 0.2 & 1.3 & 73 & 0.2 & 2.1 & 0.4 & 7 & 128 \\
\hline \multicolumn{12}{|c|}{ Group II (acetazolamide) $(n=33)$} \\
\hline $\mathbf{M}$ & 147 & 5.1 & 44 & 3.2 & $61.3^{*}$ & 959 & $7.4^{*}$ & $55.8^{*}$ & 2.5 & 308 & $640^{*}$ \\
\hline SEM & 2 & 0.4 & 1 & 0.2 & 6.3 & 44 & 0.8 & 5.9 & 0.5 & 12 & 23 \\
\hline \multicolumn{12}{|c|}{ Group III (acetazolamide and amiloride) $(n=28)$} \\
\hline $\mathbf{M}$ & 145 & 5.5 & 45 & 3.0 & $85.2^{*} \ddagger$ & 914 & $13.8^{*} \ddagger$ & $4.3 \ddagger$ & $4.9^{*} \ddagger$ & 303 & $510 * \ddagger$ \\
\hline SEM & 1 & 0.3 & 1 & 0.1 & 5.7 & 48 & 2.3 & 0.9 & 0.8 & 4 & 22 \\
\hline
\end{tabular}

P, plasma; Hct, hematocrit; P prot, plasma proteins; V, urine flow. ${ }^{*} P<0.005$ vs. group I (control). $\ddagger P<0.005$ group II vs. group III. 
Table II. Blood and Urine Acid-Base Data

\begin{tabular}{|c|c|c|c|c|c|c|}
\hline & $\mathrm{ApH}$ & $\mathrm{ApCO}_{2}$ & $\mathrm{AHCO}_{3}^{-}$ & $\mathrm{UHCO}_{3}^{-}$ & $\mathrm{UHCO}_{3}^{-} \mathrm{V}$ & $\mathrm{FEHCO}_{3}^{-}$ \\
\hline & & $\mathrm{mmHg}$ & meq/l & meq/l & $\mu e q / \min$ & $\%$ \\
\hline \multicolumn{7}{|c|}{ Group I (control) $(n=18)$} \\
\hline $\mathrm{M} \pm \mathrm{SEM}$ & $7.39 \pm 0.02$ & $38.4 \pm 2.2$ & $22.2 \pm 0.7$ & 0 & 0 & 0 \\
\hline \multicolumn{7}{|c|}{ Group II (acetazolamide) $(n=33)$} \\
\hline $\mathbf{M} \pm$ SEM & $7.36 \pm 0.01$ & $45.3 \pm 1.1^{*}$ & $24.8 \pm 0.7$ & $183.5 \pm 16.6^{*}$ & $11.4 \pm 1.1^{*}$ & $34.9 \pm 1.9^{*}$ \\
\hline \multicolumn{7}{|c|}{ Group III (acetazolamide and amiloride) $(n=28)$} \\
\hline $\mathbf{M} \pm \mathbf{S E M}$ & $7.40 \pm 0.01 \ddagger$ & $43.2 \pm 1.4$ & $25.7 \pm 0.8$ & $163.2 \pm 12.6^{*}$ & $12.9 \pm 0.9^{*}$ & $42.9 \pm 2.1 * \ddagger$ \\
\hline
\end{tabular}

A, arterial; $\mathrm{U}$, urinary; $\mathrm{UHCO}_{3}{ }^{-} \mathrm{V}$, absolute urinary excretion of $\mathrm{HCO}_{3}{ }^{-} . \quad * P<0.05$ vs. group I (control). $\ddagger P<0.05$ group II vs. group III.

micropuncture, late proximal, $\mathrm{LH}$, and early distal were significantly lower for experimental groups II and III as compared with control $(P<0.01)$. No difference was found, however, in the $\mathrm{TF} / \mathrm{P}_{\text {In }}$ ratio between group II and group III, thus demonstrating that amiloride did not further inhibit proximal water reabsorption, either in superficial or juxtamedullary nephrons. Total $\mathrm{CO}_{2}$ concentration was also significantly higher for the experimental groups II and III as compared with control at all micropuncture sites. Again, no differences in $\mathrm{tCO}_{2}$ were found between groups II and III. The $\mathrm{FDtCO}_{2}$ for groups II and III was significantly higher than control. However, there was no difference between groups II and III in $\mathrm{FDtCO}_{2}$, indicating the lack of effect of this dose of amiloride on proximal bicarbonate transport. There was no difference between $\mathrm{FDtCO}_{2}$ to the superficial early distal site and the final urine in group II (34.4 \pm 3.5 vs. $34.9 \pm 1.9 \% ; P=\mathrm{NS}$ ). Group III, however, showed net addition of bicarbonate between the superficial early distal site and the final urine $(34.8 \pm 3.0$ vs. $42.9 \pm 2.1 \% ; P<0.05)$.

Table III. Micropuncture Data

\begin{tabular}{|c|c|c|c|c|c|c|c|c|c|c|}
\hline & \multicolumn{3}{|c|}{$\mathrm{TF} / \mathrm{P}_{\mathrm{In}}$} & \multicolumn{3}{|c|}{$\mathrm{tCO}_{2}(m M)$} & \multicolumn{3}{|c|}{$\mathrm{FD}_{\mathrm{rCO} 2}(\%)$} & \multirow[b]{2}{*}{$\mathrm{FEHCO}_{3}^{-}$} \\
\hline & LP & LH & ED & LP & LH & ED & LP & LH & ED & \\
\hline & & & & & & & & & & $\%$ \\
\hline \multicolumn{11}{|c|}{ Group I (control) } \\
\hline $\mathbf{M}$ & 2.45 & 7.38 & 7.49 & 9.6 & 7.4 & 6.4 & 18.2 & 5.8 & 4.0 & 0 \\
\hline SEM & 0.16 & 1.53 & 0.36 & 1.1 & 1.4 & 2.1 & 1.3 & 1.7 & 1.4 & \\
\hline$n$ & (6) & (7) & (7) & $(6)$ & (7) & (7) & (6) & (7) & (7) & \\
\hline \multicolumn{11}{|c|}{ Group II (acetazolamide) } \\
\hline $\mathbf{M}$ & $1.81^{*}$ & $2.63^{*}$ & $3.96^{*}$ & $27.8^{*}$ & $40.2^{*}$ & $36.6^{*}$ & $68.0^{*}$ & $61.6^{*}$ & $34.4^{*}$ & $34.9^{*}$ \\
\hline SEM & 0.09 & 0.23 & 0.36 & 1.9 & 5.8 & 2.5 & 3.4 & 8.9 & 3.5 & 1.9 \\
\hline$n$ & $(12)$ & $(14)$ & $(12)$ & $(12)$ & (14) & $(12)$ & $(12)$ & (14) & $(12)$ & (33) \\
\hline \multicolumn{11}{|c|}{ Group III (acetazolamide amiloride) } \\
\hline $\mathbf{M}$ & $1.72^{*}$ & $2.77^{*}$ & $4.79^{*}$ & $28.4^{*}$ & $46.2^{*}$ & $45.4^{*}$ & $72.0^{*}$ & $60.9^{*}$ & $34.8^{*}$ & $42.9^{*} \neq \S$ \\
\hline SEM & 0.10 & 0.25 & 0.53 & 3.2 & 5.5 & 4.0 & 9.0 & 3.4 & 3.0 & 2.1 \\
\hline$n$ & $(8)$ & (11) & (11) & (8) & (11) & (11) & (8) & (11) & (11) & $(28)$ \\
\hline
\end{tabular}

LP, late proximal (superficial); ED, early distal (superficial); LH, bend of the loop of Henle (juxtamedullary); $n$, number of animals. ${ }^{*} P<0.05$ vs. group I (control). $\ddagger P<0.05$ group II vs. group III. $\$ P<0.05 \mathrm{ED}$ vs. $\mathrm{FE}_{\mathrm{HCO} 3}$. 
To localize more precisely the tubular sites for carbonic anhydrase-independent bicarbonate reabsorption, we divided proximal reabsorption by superficial nephrons into that portion reabsorbed by the proximal convoluted tubule and that reabsorbed by the loop segment (residual segments of proximal convoluted tubule inaccessible to micropuncture, plus pars recta, plus thin descending limb of the LH). Fig. 1 (top) shows that under control conditions, $81.8 \pm 1.3 \%$ of the filtered load of bicarbonate was reabsorbed by the proximal convoluted tubule while $14.0 \%$ was reabsorbed by the loop segment. The administration of acetazolamide, however, significantly decreased bicarbonate reabsorption by the proximal convoluted tubule to only $32.0 \pm 3.4 \%$ of the filtered load $(P<0.001)$, but significantly increased loop segment reabsorption to $31.7 \%(P<0.01)$. Thus, in control conditions, proximal bicarbonate reabsorption (proximal convoluted tubule plus loop segment) was $96 \pm 1.4 \%$ of the load filtered by superficial nephrons. After carbonic anhydrase

SUPERFICIAL NEPHRONS
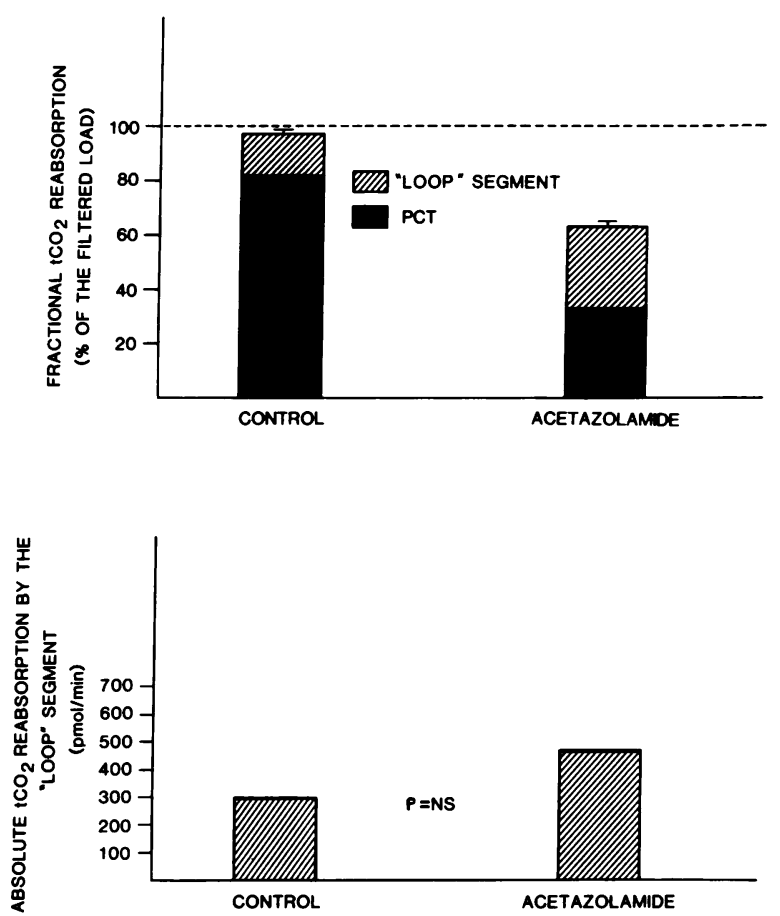

Figure 1. Proximal fractional reabsorption of total $\mathrm{CO}_{2}\left(\mathrm{FRtCO}_{2}\right)$ by superficial nephrons of control and acetazolamide-treated rats (upper). Acetazolamide infusion decreased proximal fractional bicarbonate reabsorption $(P<0.05)$. Proximal reabsorption of bicarbonate was divided into two components: first, reabsorption by the proximal convoluted tubule (PCT) (control vs. acetazolamide; $P<0.001$ ); second, reabsorption by the loop segment (residual PCT, pars recta and thin descending limb of $\mathrm{HL}$ ); (control vs. acetazolamide; $P<0.01$ ). The lower panel depicts the absolute $\mathrm{tCO}_{2}$ reabsorption by the loop segment in control and acetazolamide-treated animals $(P=$ NS). inhibition with acetazolamide, proximal reabsorption by superficial nephrons decreased to $65.6 \pm 3.5 \%$ of the filtered load $(P<0.05)$. As shown in Fig. 1 (bottom), absolute bicarbonate reabsorption by the loop segment was not significantly different between control and acetazolamide-treated rats (305.7 vs. 472.7 $\mathrm{pmol} / \mathrm{min} ; \boldsymbol{P}=\mathrm{NS}$ ). (No standard error is reported for loop segment values since they were compared using a test for interaction in an unbalanced two-way analysis of variance.)

To determine the role of juxtamedullary nephrons in the final urinary excretion of bicarbonate, proximal reabsorption of water and bicarbonate were measured and compared with that of superficial nephrons. As mentioned, we used the early distal site to determine proximal reabsorption of water and bicarbonate by superficial nephrons; the rationale for this is addressed in detail both in Methods and Discussion sections. Table III and Figs. 2 and 3 summarize these data. As shown in Fig. 2 (top), proximal $\mathrm{FRtCO}_{2}$ was similar between superficial and juxtamedullary nephrons $(96.0 \pm 1.4$ vs. $94.2 \pm 1.7 \% ; P=\mathrm{NS})$ in control animals. $\mathrm{FRtCO}$, however, was significantly higher in superficial nephrons than in juxtamedullary nephrons after acetazolamide infusion $(65.6 \pm 3.5$ vs. $38.4 \pm 8.9 \% ; P<0.02)$ and after acetazolamide and amiloride $(65.2 \pm 3.0$ vs. $39.1 \pm 3.4 \% ; P<0.001)$. Fig. 2 (bottom) shows that $\mathrm{FRH}_{2} \mathrm{O}$ followed a pattern similar to $\mathrm{FRtCO}_{2}$. The $\mathrm{FRH}_{2} \mathrm{O}$ was the same for superficial and juxtamedullary nephrons under control conditions $(86.5 \pm 0.7$ vs. $82.3 \pm 3.6 \% ; P=\mathrm{NS}$ ). Superficial nephrons, however, reabsorbed a higher fraction of the filtered load of water than juxtamedullary nephrons after the administration of acetazolamide (72.5 \pm 2.4 vs. $58.1 \pm 3.7 \% ; P<0.005)$. Similar results were observed for the acetazolamide-amiloride group $\left(\mathrm{FRH}_{2} \mathrm{O}, 76.3 \pm 2.7\right.$ vs. $60.8 \pm 5 \% ; P<0.005)$.

Fig. 3 shows that the filtered loads of $\mathrm{tCO}_{2}$ were not significantly different between both populations of nephrons in group I or group II. Absolute proximal $\mathrm{tCO}_{2}$ reabsorption was similar between superficial and deep nephrons in the control group $(1,191 \pm 111$ vs. $1,659 \pm 365 \mathrm{pmol} / \mathrm{min} ; P=\mathrm{NS})$. The absolute proximal $\mathrm{tCO}_{2}$ reabsorption in the acetazolamide-treated group, however, was significantly higher in the superficial nephrons than in the juxtamedullary nephrons $(727 \pm 82$ vs. $346 \pm 126$ $\mathrm{pmol} / \mathrm{min} ; P<0.05$ ).

In order to investigate possible driving forces favoring reabsorption of bicarbonate after inhibition of carbonic anhydrase, $\mathrm{tCO}_{2}$ concentrations were determined in VR plasma and $\mathrm{LH}$ tubular fluid in six control and six acetazolamide-infused rats in a paired fashion. Fig. 4 shows that $\mathrm{tCO}_{2}$ concentration in control animals was significantly lower in the LH as compared with VR $(7.4 \pm 1.7$ vs. $19.1 \pm 2.3 \mathrm{mM} ; P<0.005)$. After acetazolamide administration this gradient was reversed (27.0 \pm 1.4 vs. $20.4 \pm 1.0 \mathrm{mM} ; P<0.005)$.

\section{Discussion}

The sites and mechanisms of carbonic anhydrase-independent bicarbonate reabsorption by the kidney have remained contro- 

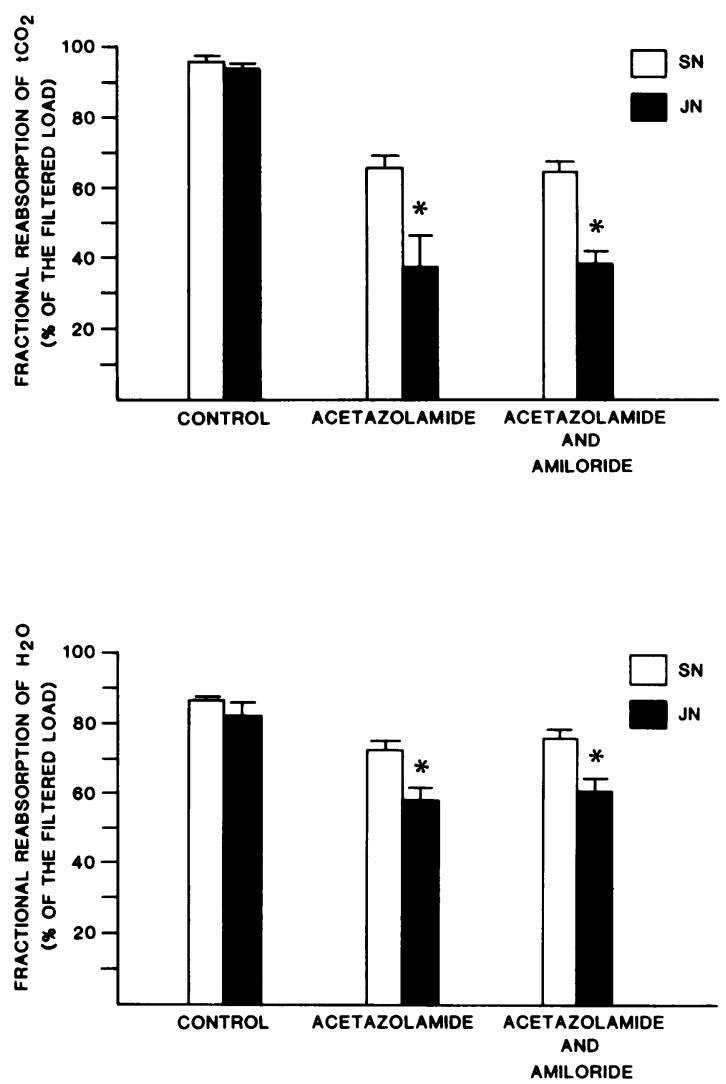

Figure 2. Comparison of proximal fractional $\mathrm{tCO}_{2}$ reabsorption $\left(\mathrm{FRtCO}_{2}\right)$ between superficial and juxtamedullary nephrons in the three groups (upper). $\mathrm{FRtCO}_{2}$ was significantly lower in juxtamedullary nephrons (JN) than superficial nephrons (SN) in both experimental groups. Proximal fractional water reabsorption $\left(\mathrm{FRH}_{2} \mathrm{O}\right)$ in both nephron populations is compared in the lower panel. Again, $\mathrm{FRH}_{2} \mathrm{O}$ was significantly less in juxtamedullary nephrons than in superficial nephrons in both experimental groups. *, SN vs. JN $(P$ $<0.05)$.

versial for years. Both in vitro and in vivo studies have demonstrated that the concentration of acetazolamide that is achieved in the kidney after systemic administration of this inhibitor in the dose that we used, is sufficient to totally inhibit the enzyme $(2,10,27)$. It is now a well-established fact that the administration of a carbonic anhydrase-inhibiting drug will increase delivery of bicarbonate to the superficial end proximal tubule to $\sim 80 \%$ of the filtered load. However, only one-third of the filtered load reaches the final urine $(2,7)$. Thus, $\sim 50 \%$ of the filtered load of bicarbonate can be reabsorbed by the kidney at sites other than the superficial proximal convoluted tubule and by mechanisms that are independent of the enzyme carbonic anhydrase.

In vivo microperfusion studies have shown that, under normal circumstances, there is no bicarbonate reabsorption by the su- perficial distal convoluted tubule of the rat (28). In vitro microperfusion studies show that bicarbonate reabsorption is totally inhibited by acetazolamide, both in the cortical and medullary collecting tubule of the rabbit $(29,30)$. Furthermore, two recent micropuncture studies have suggested that acetazolamide inhibits bicarbonate transport by the papillary $C D$ of the rat $(31,32)$. This latter finding, however, is in disagreement with preliminary studies from our laboratory (33). The recent micropuncture study by DuBose and Lucci (7) also suggests that there is significant carbonic anhydrase-independent bicarbonate reabsorption by the collecting tubule of the rat. Thus, the purpose of the present studies was to localize the tubular sites for carbonic anhydrase-independent bicarbonate reabsorption, to study the role of juxtamedullary nephrons in this process, to investigate the effects of systemic doses of amiloride on carbonic anhydraseindependent bicarbonate reabsorption, and to elucidate some
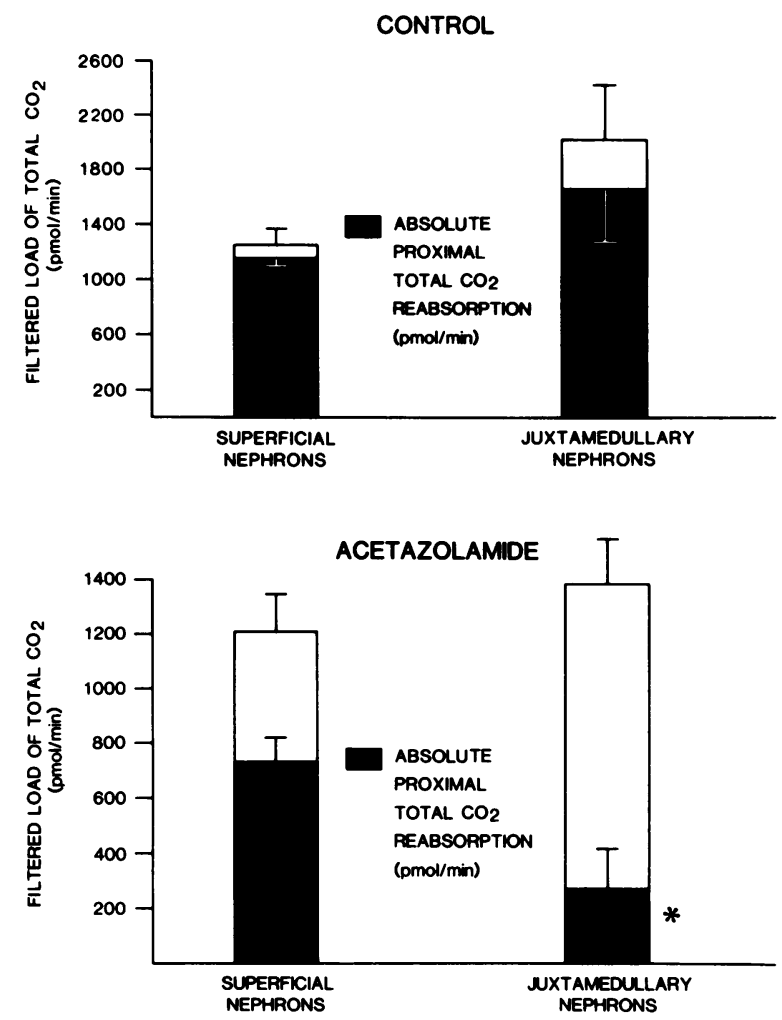

Figure 3. Comparison between absolute proximal $\mathrm{tCO}_{2}$ reabsorption by superficial and juxtamedullary nephrons in control (upper) and acetazolamide-treated rats (lower). The filtered load of bicarbonate was the same between both nephron populations in controls, and in acetazolamide-treated animals $(P=\mathrm{NS})$. Absolute proximal $\mathrm{tCO}_{2}$ reabsorption was similar between both nephron populations in controls $(P=\mathrm{NS})$. Juxtamedullary nephrons, however, reabsorbed significantly less $\mathrm{tCO}_{2}$ than superficial nephrons after administration of acetazolamide. *, superficial vs. juxtamedullary nephron absolute proximal $\mathrm{tCO}_{2}$ reabsorption $(P<0.05)$. 

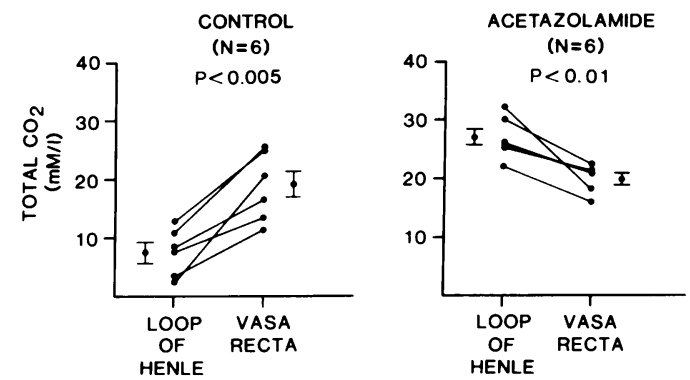

Figure 4. Total $\mathrm{CO}_{2}$ concentration gradients between $\mathrm{LH}$ fluid and VR plasma in control and acetazolamide-treated rats. Plasma values are corrected for plasma water. Each point in the figure represents the average $\mathrm{tCO}_{2}$ concentration in the $\mathrm{LH}$ or VR for each animal. These values were paired. $N$, number of animals.

of the possible mechanisms for bicarbonate reabsorption after inhibition of carbonic anhydrase.

Our results reveal several findings: first, they demonstrate that after the systemic administration of acetazolamide both the loop segment and the terminal nephron will reabsorb bicarbonate independently of carbonic anhydrase. Second, they show that in the rat there appears to be no internephron heterogeneity for water or bicarbonate transport under control conditions. The administration of acetazolamide, however, uncovers internephron heterogeneity for water and bicarbonate reabsorption. The superficial nephrons show a greater net reabsorptive capacity for water and bicarbonate than juxtamedullary nephrons under these experimental conditions. Third, amiloride, at the dose administered by us, inhibited distal carbonic anhydrase-independent bicarbonate reabsorption. Amiloride had no effect on proximal water or bicarbonate reabsorption. Fourth, under baseline conditions, the bicarbonate chemical concentration gradient between the loops of Henle and vasa recta of the papilla of the rat favors bicarbonate secretion. If carbonic anhydrase is inhibited with acetazolamide, this chemical concentration gradient reverses and favors reabsorption of bicarbonate in this tubular segment.

Effects of acetazolamide and amiloride on bicarbonate reabsorption: role of the loop segment and collecting tubule. Carbonic anhydrase inhibition with acetazolamide resulted in inhibition of bicarbonate reabsorption in the proximal convoluted tubule from 81.8 to $32 \%$. However, only $34.9 \%$ of the filtered bicarbonate appeared in the final urine. Our study indicates that both the loop segment of superficial nephrons and the terminal nephron are sites of significant bicarbonate reabsorption in acetazolamide-treated rats. Since Lucci et al. (28) have recently shown that the superficial distal convoluted tubule does not transport bicarbonate under normal conditions, the terminal site for bicarbonate reabsorption is most likely the collecting tubules.

As shown in Fig. 1, 31.7\% of the filtered load of bicarbonate is reabsorbed by the loop segment of superficial nephrons in acetazolamide-treated rats. In micropuncture studies, the loop segment is composed of a variable portion of the proximal convoluted tubule that is inaccessible to puncture, the pars recta of the proximal tubule, the $\mathrm{LH}$, and a small portion of the very early distal tubule. Any of these tubular segments could have been responsible for the observed reabsorption of bicarbonate. A previous micropuncture study has shown that the loop segment appears to be permeable to bicarbonate (34). Previous studies using the in vitro perfused tubule technique have shown that carbonic anhydrase inhibition severely impairs bicarbonate reabsorption by both the proximal convoluted tubule and the pars recta $(1,4)$. Recent work by Jacobson $(6)$, however, shows that the proximal convoluted tubule of the rabbit has a residual capacity to reabsorb bicarbonate independent of carbonic anhydrase. Indeed, our present study and those of others show in vivo that the superficial proximal convoluted tubule of the rat is still able to reabsorb $\sim 20 \%$ of the filtered load of bicarbonate after inhibition of carbonic anhydrase $(2,7)$. Thus, the proximal convoluted tubule that is inaccessible to micropuncture may be responsible for part of the reabsorption of bicarbonate observed in the loop segment. With the present technique one cannot rule out the possibility that the pars recta of the rat may also have a residual capacity to reabsorb bicarbonate independently of carbonic anhydrase.

Previous clearance studies suggest that bicarbonate is a poorly reabsorbable anion in the diluting segments of the kidney (19, 20). Recent in vitro tubule microperfusion studies of both the medullary and cortical thick ascending limb of the LH suggest low passive bicarbonate permeability and minimal bicarbonate transport $(21,22)$. Thus, it appears at present that the ascending limb of the LH may not be a site for significant carbonic anhydrase-independent bicarbonate reabsorption.

The role of the thin descending limb of the LH in the reabsorption of bicarbonate has not been established. In vitro studies in isolated tubules suggest that the passive permeability of this tubular segment to sodium and chloride are quite low and that this segment is incapable of active transport (35). The passive permeability of bicarbonate in the thin descending limb of the LH has not been studied. Since our study shows that the loop segment reabsorbs a significant amount of the filtered load of bicarbonate, it is possible that the thin descending limb of the LH could be a site for carbonic anhydrase-independent bicarbonate reabsorption.

If we consider the results obtained from the superficial nephrons to represent the whole kidney and assume no internephron heterogeneity for carbonic anhydrase-independent bicarbonate transport, our results would localize this reabsorption to the proximal convoluted tubule ( $32 \%$ of the filtered load) and to the loop segment ( $31.7 \%$ of the filtered load). This would account for all carbonic anhydrase-independent bicarbonate reabsorption, since $\sim 35 \%$ of the filtered load is excreted in the urine. This would imply that distal tubules and collecting tubules are unable to reabsorb bicarbonate after inhibition of carbonic anhydrase. Indeed, the $\mathrm{FDtCO}_{2}$ to the superficial early distal site 
(34.4\%) was not different from $\mathrm{FEHCO}_{3}(34.9 \%)$ in acetazolamide-treated rats. This hypothesis would agree with some of the existing in vivo and in vitro data showing lack of bicarbonate transport in the cortical, medullary, and papillary $\mathrm{CD}$ after inhibition of carbonic anhydrase with acetazolamide (29-31). On the other hand, DuBose and Lucci (7) using in vivo micropuncture have recently shown that there is significant carbonic anhydrase-independent bicarbonate reabsorption by the distal nephron of the rat. Previous clearance studies from our laboratory showed that the administration of acetazolamide did not decrease distal acidification (estimated from the urine minus blood $\mathrm{PCO}_{2}$ ) (36). Further studies, also from our laboratory, showed that the administration of amiloride induced significant increases in $\mathrm{FEHCO}_{3}$ in acetazolamide-treated rats (37). Amiloride, at the dose administered in those studies and in our present experiments, is thought to inhibit distal acidification $(38,39)$. The present study confirmed these findings, directly localizing the action of this dose of amiloride to the terminal nephron. Our study showed that amiloride induced net addition of bicarbonate between the superficial early distal tubule and the final urine of acetazolamide-treated rats.

The fact that amiloride was able to induce net addition of bicarbonate between the superficial early distal tubule micropuncture site and the final urine strongly suggests that the distal nephron is capable of carbonic anhydrase-independent bicarbonate reabsorption. The most likely explanation for the observed findings is that amiloride, by inhibiting distal carbonic anhydrase-independent bicarbonate reabsorption, uncovers a greater distal delivery of bicarbonate by the juxtamedullary nephrons, which would explain the net addition of bicarbonate observed between the early distal tubule of the superficial nephrons and the final urine. There is a possibility, however, if there is bidirectional bicarbonate transport in the collecting tubules, that amiloride by blocking carbonic anhydrase-independent bicarbonate reabsorption may uncover bicarbonate secretion. This would also explain the observed net addition of bicarbonate. We think, however, that the chemical concentration gradients of both bicarbonate and chloride in the CD after acetazolamide administration are unfavorable for bicarbonate secretion $(7,40)$. Thus, we favor the former explanation. It has been shown in vitro that amiloride inhibits sodium transport and lumen-negative transepithelial potential difference in the cortical collecting tubule (13). Amiloride also inhibits acidification in this tubular segment (29). Since acidification in the cortical collecting tubule appears to be at least partly voltage-dependent, we think that the lumen-negative transepithelial potential difference generated by active sodium reabsorption constitutes a driving force for carbonic anhydrase-independent bicarbonate reabsorption in this tubular segment $(38,41,42)$.

Our study also demonstrates that amiloride does not further inhibit proximal water or bicarbonate transport. As seen in Table III, TF/ $/ \mathrm{P}_{\text {In }}$ and $\mathrm{FDtCO}_{2}$ were the same for groups II and III at all micropuncture sites. Several investigators have shown that amiloride can inhibit proximal sodium transport and acid- ification (43-45). It is most likely, however, that the dose of amiloride that we administered did not reach high enough intraluminal concentrations in the proximal tubule, since no effect was seen on $\mathrm{TF} / \mathrm{P}_{\mathrm{In}}$ or $\mathrm{FDtCO}$. Water abstraction by the tubule elevates intraluminal amiloride concentration considerably, thus allowing an effect on the distal nephron at the present dose.

Role of juxtamedullary nephrons. The role of the juxtamedullary nephrons in carbonic anhydrase-independent bicarbonate reabsorption investigated by our study was also addressed recently by two other studies $(6,7)$. Our results show that superficial nephrons have a greater capacity, both in fractional and absolute terms, to reabsorb bicarbonate independently of carbonic anhydrase. This disagrees with previous studies.

Jacobson (6), using the in vitro isolated tubule microperfusion technique, demonstrated that the juxtamedullary proximal convoluted tubule of the rabbit has a greater capacity to reabsorb bicarbonate under both control and carbonic anhydrase inhibition conditions. This investigator showed that acetazolamide inhibited bicarbonate transport to a similar degree in both nephron populations, however, juxtamedullary nephrons still retained a higher residual reabsorptive capacity. These studies, however, were done in the rabbit, which is an animal with different acidification characteristics than the rat.

More importantly, DuBose and Lucci (7), in their recent study, using free-flow micropuncture techniques in the MunichWistar rat, also concluded that there is internephron heterogeneity for carbonic anhydrase-independent bicarbonate reabsorption. They state, however, that juxtamedullary nephrons have a capacity to reabsorb a greater fraction of the filtered load of bicarbonate than superficial nephrons. The differences in conclusions between our present study and the study of DuBose and Lucci (7) are based on important differences in analysis of the data that we have addressed, in part, in the Methods (calculations) section. These investigators compare the fractional reabsorption of the filtered load of bicarbonate between superficial and deep nephrons by comparing the fractional delivery of bicarbonate to the late proximal convoluted tubule in the superficial nephrons to the fractional delivery of bicarbonate to the bend of the loop of Henle of juxtamedullary nephrons. Thus, their measurements of proximal bicarbonate reabsorption do not take into account the amount of bicarbonate that can be reabsorbed by residual segments of the proximal convoluted tubule and the pars recta of superficial nephrons, tubular segments that are capable of reabsorbing bicarbonate. When we compared proximal bicarbonate reabsorption between superficial and juxtamedullary nephrons, we compared the delivery of bicarbonate to the early distal tubule of superficial nephrons with the delivery of bicarbonate to the bend of the LH of juxtamedullary nephrons. By doing this, we account for bicarbonate reabsorption by residual segments of proximal convoluted tubules and pars recta of superficial tubules, and the bicarbonate that could be reabsorbed by the thin descending limb of the LH. In this comparison we assume that there is minimal bicarbonate reabsorption by the ascending limb of the LH. This 
assumption is based on free-water clearance studies showing that bicarbonate acts as a poorly reabsorbable anion in the diluting segments of the kidney $(19,20)$. Recent studies by Friedman and Andreoli (22) showed that there is no net transport of bicarbonate at the level of the cortical thick ascending limb of the LH, and Stokes (21) suggests that bicarbonate transport by the medullary thick ascending limb of the $\mathrm{LH}$ is probably minimal. These studies were done without imposing bicarbonate concentration gradients, but Friedman and Andreoli (22) suggest that passive bicarbonate permeability by the cortical thick ascending limb of the LH is quite low.

The studies by Imai (23) in the rat thin ascending limb of the LH examined the permeabilities of several anions relative to sodium. Bicarbonate was relatively one of the less permeant anions. This, however, was not an absolute measurement, should these considerations hold; the bicarbonate delivered to the early distal site would reflect more accurately proximal bicarbonate reabsorption by the superficial nephron than the bicarbonate delivered to the late proximal convoluted tubule.

Had we determined superficial proximal bicarbonate reabsorption of the late proximal micropuncture site, our results would show no internephron heterogeneity for acetazolamideinsensitive bicarbonate reabsorption. If we accept this conclusion, or the postulation of DuBose and Lucci (7) that juxtamedullary nephrons have a higher capacity for acetazolamide-insensitive bicarbonate reabsorption, it becomes difficult to explain the net addition of bicarbonate between the superficial early distal tubule and the final urine observed after the infusion of amiloride. As discussed above, we think that significant bicarbonate secretion is unlikely in this setting. Even if bicarbonate reabsorption by the ascending limb of the LH does occur, the results of group III strongly suggest that juxtamedullary nephrons deliver a greater load of bicarbonate to the final urine than superficial nephrons.

We did not find any difference in proximal fractional delivery or absolute reabsorption of bicarbonate between both nephron populations in group I. Thus, under control conditions and with the present technique we do not find internephron heterogeneity for bicarbonate transport in the rat. In acetazolamide-treated rats, superficial nephrons reabsorbed a significantly higher fraction of the filtered load of water than the juxtamedullary nephrons (Fig. 2, bottom). Since $\mathrm{tCO}_{2}$ concentrations were similar in both nephron populations of these rats, the possibility exists that a fraction of proximal carbonic anhydrase-independent bicarbonate reabsorption by superficial nephrons may follow water reabsorption.

Possible mechanisms for carbonic anhydrase-independent bicarbonate reabsorption. In view of the fact that both the loop segment and the collecting tubule seem to reabsorb significant amounts of bicarbonate after carbonic anhydrase inhibition, we investigated the possibility of passive reabsorption by determining the chemical concentration gradient in the papilla of the rat. Fig. 4 depicts how acetazolamide administration reverses the VR plasma to $\mathrm{LH} \mathrm{tCO}$ concentration gradient so as to favor bicarbonate reabsorption. These results are in agreement with the findings of DuBose and Lucci (7). The role of this gradient, however, is not clear, since the permeability of bicarbonate in the involved tubular segments has not been established. DuBose and Lucci (7) were able to abolish the LH to VR plasma chemical gradient by administering mannitol to acetazolamidetreated rats. They did not, however, increase $\mathrm{FEHCO}_{3}$ by this maneuver. On the other hand, Stinebaugh et al. (46) induced a significant increase in urinary bicarbonate excretion by administering mannitol to acetazolamide-treated dogs. Thus, the full significance of the bicarbonate concentration gradient remains unclear, but may constitute a driving force for a fraction of carbonic anhydrase-independent bicarbonate reabsorption. Preliminary data by Cox et al., (47) assuming similar tubular permeabilities for chloride and bicarbonate, suggest that carbonic anhydrase-independent bicarbonate reabsorption may be a passive process. A better estimate of the magnitude of this transport will require knowledge of the bicarbonate permeabilities of the involved segments.

Our study also suggests that the lumen-negative transepithelial potential difference across the cortical collecting tubule constitutes an important driving force for carbonic anhydrase-independent bicarbonate reabsorption, since amiloride infusion in acetazolamide-treated rats significantly increased the fractional excretion of bicarbonate as compared with rats treated with acetazolamide alone. The delineation of the precise role of voltage in carbonic anhydrase-independent bicarbonate reabsorption requires other techniques.

The possibility of incomplete inhibition of the enzyme has been postulated by some to account for bicarbonate reabsorption after administration of acetazolamide. Studies done in slices of kidney tissue, however, have shown that concentrations of acetazolamide of $10^{-4} \mathrm{M}$ inhibit carbonic anhydrase activity totally (27). Cogan et al. (2) have demonstrated that systemic administration of acetazolamide in the dose that we used in our experiments achieves intraluminal concentrations of the magnitude that have been shown by others to completely inhibit carbonic anhydrase, both in kidney slices and in the in vivo microperfusion preparation $(8,27)$. Thus, this remains an unlikely possibility.

Finally, recycling of carbonic acid has been postulated by Rector (10) to account for carbonic anhydrase-independent bicarbonate reabsorption. This hypothesis assumes that carbonic acid diffuses from the tubular lumen readily into the cells and serves as the source of hydrogen ion. This mechanism continues to be a possibility in addition to the mechanisms for carbonic anhydrase-independent bicarbonate reabsorption that are suggested above.

\section{Acknowledgments}

We are grateful to Dr. Robert Anderson for his statistical assistance, to Ms. Mirria McNeese, Ms. Debby Verrett, and Ms. Polly Dixon for typing the manuscript. Merck, Sharp and Dohme laboratories provided amiloride for this study. 
This manuscript was supported by National Institutes of Health grant NIH AM20170.

\section{References}

1. Burg, M., and N. Green. 1977. Bicarbonate transport by the isolated perfused rabbit proximal convoluted tubules. Am. J. Physiol. 233(2):F307-F314.

2. Cogan, M. G., D. A. Maddox, D. G. Warnock, E. T. Lin, and F. C. Rector, Jr. 1979. Effect of acetazolamide on bicarbonate reabsorption in the proximal tubule of the rat. Am. J. Physiol. 237(6):F447F454.

3. Kunau, R. T., Jr. 1972. The influence of the carbonic anhydrase inhibitor, benzolamide (CL-11,366), on the reabsorption of chloride, sodium, and bicarbonate in the proximal tubule of the rat. J. Clin. Invest. 51:294-306.

4. McKinney, T. D., and M. B. Burg. 1977. Bicarbonate and fluid absorption by renal proximal straight tubules. Kidney Int. 12:1-8.

5. Chan, Y. L., B. Biagi, and G. Giebisch. 1982. Control mechanisms of bicarbonate transport across the rat proximal convoluted tubule. Am. J. Physiol. 242(11):F532-F543.

6. Jacobson, H. R. 1981. Effects of $\mathrm{CO}_{2}$ and acetazolamide on bicarbonate and fluid transport in rabbit proximal tubules. Am. J. Physiol. 240(9):F54-F62.

7. DuBose, T. D., Jr., and M. S. Lucci. 1983. Effect of carbonic anhydrase inhibition on superficial and deep nephron bicarbonate reabsorption in the rat. J. Clin. Invest. 71:55-65.

8. Lucci, M. S., D. G. Warnock, and F. C. Rector, Jr. 1979. Carbonic anhydrase-dependent bicarbonate reabsorption in the rat proximal tubule. Am. J. Physiol. 236(5):F58-F65.

9. Maren, T. H. 1974. Chemistry of the renal reabsorption of bicarbonate. Can. J. Physiol. Pharmacol. 52:1041-1050.

10. Rector, F. C., Jr. 1973. Acidification of the urine. Handbook Physiol. VIII:431-451.

11. Berry, C. A. 1982. Heterogeneity of tubular transport processes in the nephron. Annu. Rev. Physiol. 44:181-201.

12. Warnock, D. G., and M. B. Burg. 1977. Urinary acidification: $\mathrm{CO}_{2}$ transport by the rat proximal straight tubule. Am. J. Physiol. 232(1):F20-F25.

13. Stoner, L. C., M. B. Burg, and J. Orloff. 1974. Ion transport in cortical collecting tubule: effect of amiloride. Am. J. Physiol. 227:453459.

14. DuBose, T. D., Jr., L. R. Pucacco, M. S. Lucci, and N. W. Carter. 1979. Micropuncture determination of $\mathrm{pH}, \mathrm{pCO}_{2}$ and total $\mathrm{CO}_{2}$ concentration in accessible structures of the rat renal cortex. J. Clin. Invest. 64:476-482.

15. DuBose, T. D., Jr., L. R. Pucacco, D. W. Seldin, N. W. Carter, and J. P. Kokko. 1979. Microelectrode determination of $\mathrm{pH}$ and $\mathrm{pCO}_{2}$ in rat proximal tubule after benzolamide: evidence for hydrogen ion secretion. Kidney Int. 15:624-629.

16. Ichikawa, I., D. A. Maddox, M. G. Cogan, and B. M. Brenner. 1978. Dynamics of glomerular ultrafiltration in euvolemic Munich-Wistar rats. Renal Physiol. 1:121-131.

17. Johnston, P. A., C. A. Battilana, F. B. Lacy, and R. L. Jamison. 1977. Evidence for a concentration gradient favoring outward movement of sodium from the thin loop of Henle. J. Clin. Invest. 59:234-240.

18. Vurek, G. G., D. G. Warnock, and R. Corsey. 1975. Measurement of picomole amounts of carbon dioxide by calorimetry. Anal. Chem. 47:765-767.
19. Rosin, J. M., M. A. Katz, F. C. Rector, Jr., and D. W. Seldin. 1970. Acetazolamide in studying sodium reabsorption in diluting segment. Am. J. Physiol. 219:1731-1745.

20. Seldin, D. W., J. M. Rosin, and F. C. Rector, Jr. 1975. Evidence against bicarbonate reabsorption in the ascending limb, particularly as disclosed by free-water clearance studies. Yale J. Biol. Med. 48:337347.

21. Stokes, J. B. 1982. Consequences of potassium recycling in the renal medulla. J. Clin. Invest. 70:219-229.

22. Friedman, P. A., and T. E. Andreoli. 1982. $\mathrm{CO}_{2}$-stimulated $\mathrm{NaCl}$ absorption in the mouse renal cortical thick ascending limb of Henle. J. Gen. Physiol. 80:683-711.

23. Imai, M. 1977. Function of the thin ascending limb of Henle of rats and hamsters perfused in vitro. Am. J. Physiol. 232(1):F201F209.

24. Rocha, A. S., and J. P. Kokko. 1973. Sodium chloride and water transport in the medullary thick ascending limb of Henle. J. Clin. Invest. 52:612-623.

25. Hastings, A. B., and J. Sendroy, Jr. 1925. The effect of variation in ionic strength on the apparent first and second dissociation constants of carbonic acid. J. Biol. Chem. 65:445-455.

26. Kleinbaum, D. G., and L. Kupper. 1978. Applied regression analysis and other multivariable methods. Duxbury Press. North Scituate, MS.

27. Maren, T. H. 1977. Use of inhibitors in physiological studies of carbonic anhydrase. Am. J. Physiol. 232(1):F291-F297.

28. Lucci, M. S., L. R. Pucacco, N. W. Carter, and T. D. DuBose, Jr. 1982. Evaluation of bicarbonate transport in rat distal tubule: effects of acid-base status. Am. J. Physiol. 243(12):F335-F341.

29. McKinney, T. D., and M. B. Burg. 1978. Bicarbonate absorption by rabbit cortical collecting tubules in vitro. Am. J. Physiol. 234(3):F141F145.

30. Lombard, W. E., J. P. Kokko, and H. R. Jacobson. 1983. Bicarbonate transport in cortical and outer medullary collecting tubules. Am. J. Physiol. 244(13):F289-F296.

31. Ullich, K. J., and F. Papavassiliou. 1981. Bicarbonate reabsorption in the papillary collecting duct of rats. Pfluegers Arch. Eur. J. Physiol. 389:271-275.

32. Richardson, R. M. A., and R. T. Kunau, Jr. 1982. Bicarbonate reabsorption in the papillary collecting duct: effect of acetazolamide. Am. J. Physiol. 243(12):F74-F80.

33. Wesson, D. E., M. E. Laski, N. A. Kurtzman, and J. P. Frommer. 1983. Bicarbonate reabsorption by the papillary collecting duct of the Munich-Wistar rat. Clin. Res. 31:444a. (Abstr.)

34. Levine, D. Z., M. K. Byers, R. A. McLeod, and J. A. Luisello. 1979. Loop of Henle bicarbonate accumulation in vivo in the rat. $J$. Clin. Invest. 63:59-66.

35. Kokko, J. P. 1970. Sodium chloride and water transport in the descending limb of Henle. J. Clin. Invest. 49:1838-1846.

36. Rubinstein, H., D. C. Batlle, M. Roseman, J. T. Sehy, J. A. L. Arruda, and N. A. Kurtzman. 1981. Urinary $\mathrm{pCO}_{2}$ during carbonic anhydrase inhibition in the dog. Miner. Electrolyte Metab. 5:49-59.

37. Cruz-Soto, M., J. P. Frommer, K. Itsarayoungyen, D. C. Batlle, J. A. L. Arruda, and N. A. Kurtzman. Carbonic anhydrase-independent bicarbonate reabsorption in rats with chronic papillary necrosis. Miner. Electrolyte Metab. In press.

38. Arruda, J. A. L., K. Subbarayudu, G. Dytko, R. Mola, and N. A. Kurtzman. 1980. Voltage-dependent distal acidification defect induced by amiloride. J. Lab. Clin. Med. 95:407-416. 
39. Hulter, H. N., L. P. Ilnicki, J. H. Licht, and A. Sebastian. 1982. On the mechanism of diminished carbon dioxide tension caused by amiloride. Kidney Int. 21:8-13.

40. Laski, M. E., D. G. Warnock, and F. C. Rector, Jr. 1983. Effects of chloride gradients on total $\mathrm{CO}_{2}$ flux in the rabbit cortical collecting tubule. Am. J. Physiol. 244(13):F112-F121.

41. Koeppen, B. M., and S. I. Helman. 1982. Acidification of luminal fluid by the rabbit cortical collecting duct perfused in vitro. Am. J. Physiol. 242(11):F521-F531.

42. Laski, M. E., and N. A. Kurtzman. 1983. Characterization of acidification in the cortical and medullary collecting tubule of the rabbit. J. Clin. Invest. 72:2050-2059.

43. Chan, Y. L., and G. Giebisch. 1981. Relationship between sodium and bicarbonate transport in the rat proximal convoluted tubule. $\mathrm{Am}$. J. Physiol. 240(9):F222-F230.

44. Kinsella, J. L., and P. S. Aronson. 1981. Amiloride inhibition of the $\mathrm{Na}^{+}-\mathrm{H}^{+}$exchanger in renal microvillus membrane vesicles. $\mathrm{Am}$. J. Physiol. 241(10):F374-F379.

45. Howlin, K. J., R. J. Alpern, and F. C. Rector, Jr. 1983. Amiloride inhibits proximal convoluted tubule acidification in the presence of a physiologic $\mathrm{Na}^{+}$concentration. Clin. Res. 31:75a. (Abstr.)

46. Stinebaugh, B. J., S. A. Bartow, G. Eknoyan, M. MartinezMaldonado, and W. N. Suki. 1971. Renal handling of bicarbonate: effect of mannitol diuresis. Am. J. Physiol. 220:1271-1274.

47. Cox, C., D. W. Seldin, and H. R. Jacobson. 1981. Passive reabsorption of bicarbonate after maximal carbonic anhydrase inhibition. Int. Cong. Nephrol, 8th, Athens, Greece. 44a. (Abstr.) 